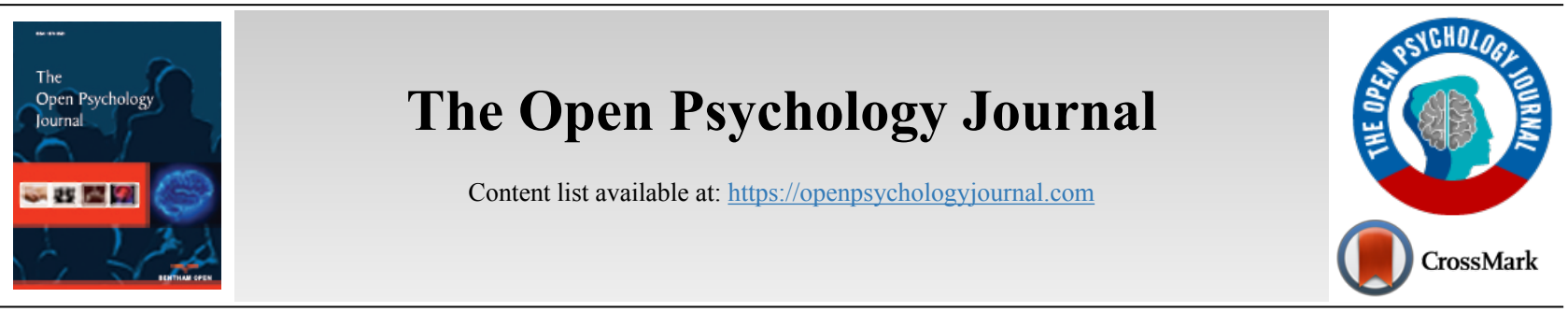

RESEARCH ARTICLE

\title{
Health-Related Social Control Influences the Physical Activity of College Students
}

\author{
Kelly A. Cotter ${ }^{1, *}$ and Jennifer A. Mendiola ${ }^{2}$ \\ ${ }^{l}$ California State University, Stanislaus, CA, USA \\ ${ }^{2}$ University of California, Merced, CA, USA
}

\begin{abstract}
:
Objective:

To examine the impact of health-related social control tactics on the physical activity behavior of college students.

Participants:

110 undergraduates (74\% women) recorded their naturalistic behavior across eight consecutive days between March and May of 2010 .

Methods:

A short-term longitudinal daily diary survey examined daily self-reports of received health-related social control (the direct regulation of a target's health behaviors by a social partner) and minutes engaged in physical activity.

Results:

Multilevel modeling according to a two-level structure in which observations (Level 1) were nested within individuals (Level 2) revealed that positive social control for exercise (e.g., encouragement) had a positive effect on physical activity participation, both within-persons (intraindividual level) and between-persons (inter-individual level). Negative social control (e.g., nagging) had no effect on physical activity participation.

\section{Conclusion:}

The present results suggest that individuals should employ positive social control tactics when attempting to enhance the physical activity behaviors of college students.
\end{abstract}

Keyword: Health-related social control, Physical activity, Daily diary, Young adults, Multilevel modeling, Chronic illness.

\begin{tabular}{|l|l|l|r|}
\hline Article History & Received: April 05, 2019 & Revised: August 09, 2019 & Accepted: August 27, 2019 \\
\hline
\end{tabular}

\section{INTRODUCTION}

Research has demonstrated many physical and mental health benefits from engaging in regular physical activity across the lifespan, including increased longevity, reduced risk for chronic illness, improved well-being, and enhanced cognitive functioning [1]. Given the benefits of engaging in regular physical activity, the Centers for Disease Control and Prevention [2] recommend that adults engage in at least 2.5 hours of moderate-intensity aerobic activity (i.e., walking briskly) or 1.25 hours of vigorous-intensity aerobic activity Address correspondence to this author at the California State University,
Stanislaus one university circle, Turlock, CA, USA; Tel: 209-6673865;

E-mail: Kcotter@csustan.edu (i.e., running) every week, in addition to muscle-strengthening activities that work all major muscle groups. Despite this recommendation, adolescents typically encounter lifestyle changes as they transition to college in young adulthood that are associated with less physical activity, like reduced participation in organized sports [3]. Physical activity habits established early in life promote life-long physical activity and health, particularly among those most active [4]. Thus, efforts to improve physical activity habits should target college students, who are predominantly late-adolescents and young adults. Targeting this stage of life may buffer against reductions in healthy activity habits and may also fortify existing healthy habits for the future. 


\section{BACKGROUND}

One strategy used to motivate health behavior change is health-related social control [5], which is an attempt to influence the health behavior of a social partner [6, 7]. Healthrelated social control can function indirectly, like when an individual changes health practices because of a sense of responsibility to and/or modeling from others [7]. For example, a pregnant woman may quit smoking due to a sense of responsibility to her developing fetus or because her friends (social models) have recently quit smoking. Social control can also function directly, like when an individual changes health practices because of explicit tactics used by a social partner [7, 8]. These direct tactics are conceptualized in the literature as positive (e.g., reinforcing healthy behavior, offering to participate in the behavior with the target, providing helpful information about a behavior) and negative (e.g., ridiculing unhealthy practices, making negative social comparisons, nagging), and are distinct from perceived social support and social strain $[8,9]$.

Positive and negative direct social control strategies are used equally often by social partners [5], but they may not be equally effective at eliciting behavior change. Positive social control has been associated with healthy behavior change, including engaging in more physical activity, in multiple studies using diverse types of samples [10 - 13]. For example, in a structural equation model examining cross-sectional data from late-adolescent college students, Pugliese and Okun [14] found that more positive social control predicted more vigorous physical activity (defined as a strenuous activity where the "heart beats rapidly").

Negative social control has yielded more mixed findings $[9,11,15]$. For example, in a study of Japanese older adults, negative social interactions predicted more physical activity [9]. However, in a study of American adults, age and sex of the participant interacted with social control, such that more negative social control was associated with less physical activity for older men, but was not associated with physical activity for younger men or for women [15]. Still others have found that negative social control is largely ineffectual in inducing healthy behavior change [11] and at times can backfire: More negative social control has been associated with more negative affect, more hiding of unhealthy behaviors, and less engagement in healthy behaviors [14, 16 - 18].

A recent meta-analysis of 35 studies on health-related social control published between 1990 and 2013 consisted of 11 longitudinal studies, 23 cross-sectional studies, and 1 study that was not specified by the authors as either longitudinal or cross-sectional. The results of the meta-analysis confirmed that positive social control was associated with healthy behavior change, and the effect size for this relationship was small-tomoderate $(d=0.31)$ [8]. On the other hand, the relationship between negative social control and healthy behavior change was null $(d=-0.08)$, although it tended toward the negative direction. While negative social control was not associated with changing the specific targeted behavior, it was associated with more backfiring (including hiding unhealthy behavior and/or doing the opposite of what was requested) with a large effect size $(d=0.65)$. Negative social control was also associated with less psychological well-being $(d=-0.24)$, more negative affect $(d=0.56)$, less positive affect $(d=-0.45)$, and less relationship satisfaction $(d=-0.47)$.

The results of the meta-analysis [8] suggest that positive social control can be helpful for motivating healthy behavior change in targets, but that negative social control is not helpful and can even have harmful side-effects. However, most of the studies that have been conducted on the association between health-related social control and behavior change have been cross-sectional, and thus cannot imply causation. Furthermore, the longitudinal studies that have been conducted have often examined change in behavior over extended time (e.g., months) [18 - 24]. While it is important to know the longer-term outcomes of social control, it is equally important to know the immediate effects. For example, will a social control tactic result in behavior change today? Understanding how quickly social control elicits behavior change may help to inform behavioral intervention.

Few studies have examined how daily social control influences same-day behavior [8]. In one of these studies, 61 married couples wherein one partner was planning to begin a weight-loss program were surveyed every day for two weeks [12]. Results revealed that reporting more reinforcing tactics (e.g., complimenting weight loss progress) was associated with more engagement in physical activity in that same day. However, the sample was older than adolescence, potentially limiting generalizability to college students. Furthermore, the questionnaires asked specifically about spousal provision of social control, also potentially limiting generalizability to college students, who tend not to be married. Thus, taken together, these methodological characteristics may limit the potential for generalizing the results to college students, who are typically young and unmarried.

Another study examined 55 older adults with type II diabetes mellitus and their spouses [25]. Participants reported health-related social control for seven consecutive days using a daily diary method. Results revealed that social control was not associated with engagement in same-day physical activity. This study did not distinguish between positive and negative social control tactics and instead examined both types of tactics in combination. The fact that positive and negative social control were not separated, coupled with the sample characteristics (older adults with a chronic illness), limits the potential for generalizing the findings to most college students and fails to inform future intervention regarding the efficacy of positive versus negative tactics.

Finally, most of the existing literature provides information regarding inter-individual/between-persons variation. This approach is useful in determining for whom social control is an effective means of encouraging physical activity, but does not elucidate the possible mechanisms by which social control predicts physical activity. Examining intra-individual/withinpersons variation is important for understanding processes within-persons, which may not necessarily correspond to between-persons processes [26]. In order to best inform interventions, data must come from both the person-average (inter-individual/between-persons) and momentary/same-day (intra-individual/ within-persons) levels [27]. 


\subsection{The Present Study}

Taken together, previous research suggests that positive social control can motivate healthy behavior change, including physical activity [8]. However, to date, this association has not been examined on a daily basis in a college student sample. Furthermore, the results with respect to negative social control have been mixed and require further investigation. Understanding both the inter-individual and the intra-individual associations of daily physical activity and daily social control (both positive and negative) will help to generate strategies to help young adults adopt and maintain regular physical activity behavior. Thus, in the present study, we examined whether positive and negative social control on any given day would relate to engagement in physical activity both within-persons and between-persons.

Based on previous research, we predicted that respondents reporting higher positive social control and lower negative social control would report more physical activity, both withinpersons and between-persons. In other words, if a person experienced more positive social control and/or less negative social control than usual on one day (within-person), he or she should be more active that same day. Furthermore, on average, across individuals and days (between-persons), we hypothesized that higher levels of positive and lower levels of negative social control would predict higher levels of physical activity.

\section{DATA AND METHODS}

The present data were collected using a short-term longitudinal daily diary survey design. Upon volunteering to participate in the study, participants met with a research assistant, provided informed consent, and were instructed to access an online survey. This practice survey allowed participants to ask questions and to clarify confusion with a research assistant and included questions regarding demographic information as well as levels of typical physical activity in any given week. Participants then completed seven additional identical surveys: one at the end of each day for seven consecutive days. All participants were treated in accordance with ethical guidelines and their responses were kept confidential. The study was approved by the university's Institutional Review Board.

\subsection{Participants}

Participants were 110 undergraduates of age 19 to 47 years $(M=22.78, S D=5.13)$, who volunteered for the study for extra credit in their classes. Participants were predominantly female $(74.1 \%)$, and not currently living with a romantic partner (84.3\%). [Data from two participants were not included in analyses due to (1) failure to answer any social control questions and (2) extreme outliers on physical activity.] The majority of participants were White $(53.7 \%)$, while others were Black (2.8\%), Latino (16.7\%), Native American (0.9\%), Asian (13.0\%), Middle Eastern (1.9\%), Multiracial (9.3\%), or Other $(1.9 \%)$. The undergraduate sample reflects an accurate representation of the age and ethnicity of the undergraduate population of the university at the time of data collection (Voluntary System of Accountability Program College Portrait,
2016). However, women are over-represented in the present sample, because the sample was drawn from psychology classes, which tend to have more women than men [28].

\subsection{Measures}

\subsubsection{Health-related social control}

Health-related social control over exercise was measured with items adapted by Cotter [15] from Sallis and colleagues [29] measuring how many times "a significant social partner in your life" engaged in specific social control tactics "today" on a 0 (0 times) -5 ( 5 or more times) scale, across eight days. ${ }^{1}$ Positive social control was measured with 13 items (e.g., "give you encouragement to stick with your exercise program," see Appendix), with averaged weekly responses ranging from 0.00 - 3.00 (grand $M=0.33, S D=0.45$, daily $\alpha=.87-.95$ ) and negative social control was measured with 7 items (e.g., "pressure you to exercise," see Appendix), with averaged weekly responses ranging from $0.00-3.29$ (grand $M=0.30$, $S D=0.47$, daily $\alpha=.57-.88$ ). There were up to eight withinpersons social control scores; one for each day (day 0 - day 7). In addition to these same-day/within-persons measures, between-persons positive and negative social control scores were calculated by averaging the daily values for each person to indicate their average levels of positive and negative social control across the week, yielding one mean score per person.

\subsubsection{Physical activity}

Physical activity was measured daily with nine items assessing how many minutes participants engaged in (1) vigorous, (2) moderate, and (3) light physical activity that day (1) at work or school, (2) while performing chores around the home, and (3) during leisure time [15]. Vigorous activity was defined for participants as activity that "causes your heart to beat so rapidly that you can feel it in your chest and you perform the activity long enough to work up a good sweat and are breathing heavily (e.g., competitive sports like running, vigorous swimming, or high-intensity aerobics; digging in the garden, or lifting heavy objects)." Moderate activity was defined for participants as activity that "is not physically exhausting, but it causes your heart rate to increase slightly and you typically work up a sweat (e.g., leisurely sports like light tennis, slow or light swimming, low impact aerobics, or golfing without a power cart, brisk walking, mowing the lawn with a walking lawnmower)." Light physical activity included only examples: leisurely sports like croquet, strolling, shopping, light cleaning or yard work.

Consistent with Maher et al. [30], the number of minutes participants reported spending in each activity (vigorous work/ school, vigorous home, vigorous leisure, moderate work/ school, moderate home, moderate leisure, light work/school, light home, light leisure) was weighted by standard metabolic

\footnotetext{
Cotter (2012) [15] measured social control from the spouse/partner, family, and friends separately. We modified the items to include all types of social partners, using the language "a significant social partner in your life." Cotter also measured social control "in general." For example, "How much does your partner encourage you to exercise?" ( $1=$ Never $-5=$ Very Often $)$. We modified the response to consider only "today," with responses ranging from 0 times -5 or more times.
} 
equivalents (vigorous $=8.0$, moderate $=4.0$, light $=3.3$ ) and summed to create a total physical activity metabolic equivalent minutes/day score [31]. Scores were then rescaled (divided by 100) to standardize and facilitate interpretation of model coefficients. Through these calculations, participating in 75 minutes of vigorous or 150 minutes of moderate activity would yield a score of 6.0 , which would be equivalent to the CDC's 2018 recommendation for an accumulated activity for a week [2]. Scores in the present sample ranged from $0.00-56.90(M$ $=6.21, S D=7.39$ ), suggesting the participants, on average, met weekly recommendations for physical activity. However, there was a wide range of responses, with some participants reporting no weekly activity and others reporting very high levels.

\subsection{Analyses}

Examining between-persons processes is relatively straightforward: health-related social control is correlated with physical activity, similar to any other correlational study. Using the between-persons approach, we calculated each person's average positive and negative social control score across days and examined the associations with physical activity scores across days. Examining within-persons processes is more complicated: people's deviations from average levels of healthrelated social control are correlated with same-day physical activity scores. To explain, a person's social control on any given day may be higher or lower than his or her average within that week. Thus, using the within-persons approach, daily deviations from people's average level of social control for the week were correlated with their same-day physical activity score.

Multilevel analyses were conducted using the PROC MIXED command in SAS 9.4 according to a two-level structure in which observations (Level 1) were nested within individuals (Level 2) in order to examine the associations of within-persons and between-persons health-related social control with physical activity. The model compared the simultaneous associations of same-day and across-person averages of positive and negative social control. Including both same-day and across-person averages allowed for the partitioning of within-persons/intra-individual and betweenpersons/inter-individual associations between social control and physical activity [26, 27]. Specifically, this model explains the inter-individual effects of one's generally positive and negative social control levels on physical activity (the betweenpersons average level), as well as the simultaneous association of deviations from this general social control level on a particular day (the intra-individual effects).

Participants were asked to complete surveys on eight consecutive days. However, some participants skipped some surveys, resulting in an average of $4.99(S D=2.81)$ response days for physical activity (549 observations) and $4.75(S D=$ 2.87) response days for social control (522 observations for each positive and negative tactics), yielding a total of 1593 observations. Multilevel modeling has been recommended for data with missing observations such as these because it does not exclude people with missing data, which would reduce and potentially bias the sample [32].
Demographic characteristics of age, race/ethnicity, and income were examined as covariates, but they were not significantly related to physical activity. As such, only results for positive and negative social control are presented here. Based on modeling recommendations from Bolger and Laurenceau [33], we also made the following modeling decisions. Firstly, the model controlled for time, which was calculated by rescaling time (as measured in days, $n=8$ ) so that 0 was the middle of the survey period [33]. Secondly, a random intercept was included because participants differed in their baseline levels of physical activity. Thirdly, an autoregressive covariance matrix was also included because measurements closer together in time (i.e., daily) are assumed to be more correlated than measurements that are further apart (i.e., yearly). Lastly, a pseudo- $r^{2}$ statistic was calculated as an estimate of effect size, representing the proportion of the total outcome variance accounted for by each model's predictors. This statistic computes a predicted outcome value for each measurement for each person and then squares the sample correlation between the predicted and observed values [27, 34].

\section{RESULTS}

The multilevel model significantly predicted daily total physical activity (Table 1), demonstrating that within-persons, on days when positive social control was higher than usual, participants engaged in more physical activity that day $(p<$ $.01)$. Negative social control, on the other hand, was unrelated to same-day physical activity $(p=.83)$. Likewise, betweenpersons, participants' average levels of positive social control were positively associated with physical activity at the trend level $(p=.06)$, but participants' average levels of negative social control were unrelated to physical activity $(p=.45)$. While we had no a-priori hypotheses regarding interactions, we thought it important to explore two interactions between positive and negative social control on physical activity: 1) same-day/within-persons; and 2) average level/betweenpersons. Neither interaction was statistically significant (sameday: $p=.12$; average level: $p=.51$ ). Of note, time was not significant either, suggesting that the present results were not confounded by effects of the measurement process.

\section{DISCUSSION}

\subsection{Health-related Social Control}

Results regarding health-related social control revealed that experiencing more positive social control over physical activity from a significant social partner predicted significantly greater participation in same-day physical activity. Positive social control was also positively related to physical activity betweenpersons at a level approaching statistical significance. These results are consistent with previous research demonstrating the benefits of positive social control for health behaviors [8], and suggest that the effects of positive social control are quite potent. Thus, individuals who want to enhance the physical activity behavior of their social partners should rely on positive tactics in order to most effectively inspire such change. Moreover, the present results demonstrate that daily positive interaction has immediate positive health consequences and suggest that people should take advantage of their many 
opportunities to encourage friends, family, romantic partners, and co-workers toward physical activity every day.

Results further revealed that negative social control had no statistically significant relationship with physical activity, whether at the inter- or intra-individual level. Previous research has demonstrated that negative social control can result in varied outcomes, but that most commonly it can be ineffectual or can result in backfiring and reduced well-being [8]. Specifically, in college students, the present results corroborate the null effect of negative social control reported by Cotter [15]. Thus, negative health-related social control tactics should be avoided when possible. Of note, we measured participant's reports of received health-related social control, and the recipient of such messages may interpret them in multiple ways, including differently from the partner's intended meaning. To explain, a student may receive a comment from a friend such as, "You should go to the gym today." This comment may be interpreted both positively, as an expression of love and support, and negatively, as a personal attack or criticism. Future research should parse the expression of social control messages from the interpretation in order to better understand the dynamics of these messages. Furthermore, social control may look different in the virtual world of social media than it does in face-to-face interactions, especially for young people who are growing up with this technology. Exploring the impact of technology on these interactions would be an interesting avenue of research to explore in the future.

Table 1. Model statistics for multilevel models examining total physical activity.

\begin{tabular}{|c|c|c|}
\hline- & $\begin{array}{c}\text { Parameter } \\
\text { Estimate }\end{array}$ & $\begin{array}{c}\text { Standard } \\
\text { Error }\end{array}$ \\
\hline Intercept & $3.92^{* *}$ & 0.65 \\
\hline Time & .09 & 0.15 \\
\hline $\begin{array}{c}\text { Within-persons positive social } \\
\text { control }\end{array}$ & $3.46^{* *}$ & 1.17 \\
\hline $\begin{array}{c}\text { Within-persons negative social } \\
\text { control }\end{array}$ & .26 & 1.25 \\
\hline $\begin{array}{c}\text { Between-persons positive social } \\
\text { control }\end{array}$ & $5.17^{+}$ & 2.77 \\
\hline $\begin{array}{c}\text { Between-persons negative social } \\
\text { control }\end{array}$ & -1.97 & 2.58 \\
\hline Akaike information criterion (AIC) & 3423.60 & \\
\hline Bayesian information criterion (BIC) & 3434.40 & \\
\hline Pseudo $r^{2}$ & .14 & \\
\hline
\end{tabular}

Note: $* * p \leq .01,{ }^{+} p \leq .10$. Time was rescaled so that 0 was the middle of the 8 day survey period. Within-persons positive and negative social control were measured as daily reports that ranged from 0 to 5 . Between-persons positive and negative social control scores were calculated by averaging values across the week for each person to indicate their general levels of positive and negative social control across the week.

\subsection{Limitations}

The present results must be considered within the context of some important limitations. Firstly, all data were gathered via surveys and are therefore subject to self-report bias. This is most problematic when considering the physical activity data, as participants may have interpreted the definitions for the different types of physical activity differently. While efforts were made in the present study to ensure that participants correctly reported their physical activity, including discussing the definitions with participants in person and providing them with opportunities to ask questions before they completed the daily diaries, it would be best to measure physical activity with objective means like accelerometers in the future. Furthermore, the analyses were based on incomplete data, as participants could and did skip questions within surveys, surveys within days, and entire days of surveys. While multilevel modeling can account for issues with missing data [32], the results should be interpreted conservatively. Additionally, the sample was predominantly women, and so the results may not generalize to men.

\subsection{Future Directions}

Despite these limitations, the present study revealed some important patterns that can inform therapeutic and public health interventions, as well as future research. Results demonstrated that participants reporting high positive social control were much more active than those reporting low positive social control. This result suggests that the people who are most active are involved in high-quality relationships, wherein interactions are mostly positive. There is a small existing literature on relationship quality as it relates to social control, which demonstrates that higher satisfaction and intimacy in relationships is associated with more effective compliance strategies [35, 36]. Future research should investigate relationship quality for its associations with health-related social control and health behaviors.

Furthermore, the present results are based on naturalistic physical activity behavior. Participation was not limited to students who were trying to change their physical activity behavior. Strategies for behavior change are differentially effective depending on whether someone is consciously making an effort to change a behavior [37]. Thus, healthrelated social control may function differently when people are actively trying to make a change in their behavior compared to when they are not. We predict that social control messages are more salient and that people may be more receptive to these messages when they are actively trying to make a behavior change, and that future research should examine this possibility and also compare the impact of social control messages across people actively trying to change their behavior to people maintaining the status quo. Future research should also manipulate social control tactics experimentally in order to examine potential causal effects.

\section{CONCLUSION}

A major contribution of the present study is the use of daily diary methods and multilevel modeling statistical techniques. A large literature examines health-related social control cross-sectionally and a smaller literature examines it longitudinally over the course of several months (see Craddock et al. 2015 for a meta-analysis of both types of studies) [8]. The daily diary design and the multilevel analyses we utilized have important and unique implications for intervention because we were able to examine the relationships between social control and physical activity at both the average level as well as within a week [26]. Taken together, our study extends the approaches of correlational and macro-longitudinal research by employing 
methods and analyses that explain the dynamic relationships between social control and physical activity.

Badr et al. [5] found that people tend to use both positive and negative health-related social control tactics with approximately the same frequency as each other in their social relationships. Furthermore, social partners tend to use these social control tactics often in their relationships [5]. The present results suggest that social partners should engage in positive social control tactics when trying to increase a target's physical activity behavior because, in the present study, receiving high levels of positive social control for exercise had a positive effect on physical activity participation, both withinand between-persons. Based on these results, public health campaigns could focus on teaching methods for enhancing positive social control tactics within relationships. Targeting young adults may be particularly influential for public health over time, as it may reduce the risk of developing expensive and disabling chronic conditions, such as obesity, diabetes, and heart disease.

\section{ETHICS APPROVAL AND CONSENT TO PARTI- CIPATE}

The study was approved by the University's Institutional Review Board.

\section{HUMAN AND ANIMAL RIGHTS}

No animals/humans were used for studies that are the basis of this research.

\section{CONSENT FOR PUBLICATION}

Not applicable.

\section{AVAILABILITY OF DATA AND MATERIALS}

Not applicable.

\section{FUNDING}

This study was partially supported by the 2011 CSUS SSIS Summer Research Development Grant.

\section{CONFLICT OF INTEREST}

The author declares no conflict of interest, financial or otherwise.

\section{ACKNOWLEDGEMENTS}

* Jennifer Mendiola died tragically in the Ghost Ship fire in Oakland, CA on Dec. 2, 2016. This paper is dedicated to her memory. Thanks to the Active Aging Lab for their help with data collection and to the participants.

\section{APPENDIX}

\section{Positive Social Control}

The following questions are answered on a 0 - 5 scale:

\begin{tabular}{|c|c|c|c|c|c|c|}
\hline 0 times & 1 time & 2 times & 3 times & 4 times & $\begin{array}{c}5 \text { or more } \\
\text { times }\end{array}$ & Not Applicable \\
\hline
\end{tabular}
life..

How many times did a significant social partner in your
[1] Exercise with you today?

[2] Offer to exercise with you today?

[3] Give you encouragement to stick with your exercise program today?

[4] Change his or her schedule so you could exercise together today?

[5] Give you helpful reminders to exercise today?

[6] Plan for exercise on recreational outings today?

[7] Discuss exercise with you today?

[8] Talk about how much they like to exercise today?

[9] Help plan activities around your exercise today?

[10] Ask you for ideas on how they can get more exercise today?

[11] Take over chores so you had more time to exercise today?

[12] Make positive comments about your physical appearance today?

[13] Give you rewards for exercising today?

\section{Negative Social Control}

The following questions are answered on a $0-5$ scale:

\begin{tabular}{|c|c|c|c|c|c|c|}
\hline 0 times & 1 time & 2 times & 3 times & 4 times & $\begin{array}{c}5 \text { or more } \\
\text { times }\end{array}$ & Not Applicable \\
\hline
\end{tabular}
life..

How many times did a significant social partner in your

[1] Nag you about exercise today?

[2] Demand that you exercise on recreational outings today?

[3] Demand that you discuss exercise today?

[4] Tell you ideas on how you can get more exercise today?

[5] Make negative comments about your physical appearance today?

[6] Pressure you to exercise today?

[7] Make remarks about how much you should be exercising today?

\section{REFERENCES}

[1] American College of Sports Medicine. ACSM's Guidelines for Exercise Testing and Prescription. Philadelphia: Lippincott, Williams, and Wilkins 2000

[2] Centers for Disease Control and Prevention. 2018. "Physical activity for everyone." Retrieved January 22, 2018. www.cdc.gov/nccdphp/dnpa/physical/everyone/recommendations/

[3] Kjønniksen L, Anderssen N, Wold B. Organized youth sport as a predictor of physical activity in adulthood. Scand J Med Sci Sports 2009; 19(5): 646-54.

[http://dx.doi.org/10.1111/j.1600-0838.2008.00850.x] [PMID: 18694430]

[4] Telama R, Yang X, Viikari J, Välimäki I, Wanne O, Raitakari O. Physical activity from childhood to adulthood: A 21-year tracking study. Am J Prev Med 2005; 28(3): 267-73.

[http://dx.doi.org/10.1016/j.amepre.2004.12.003] [PMID: 15766614]

[5] Badr H, Yeung C, Lewis MA, Milbury K, Redd WH. An observational study of social control, mood, and self-efficacy in couples during treatment for head and neck cancer. Psychol Health 2015; 30(7): 783-802.

[http://dx.doi.org/10.1080/08870446.2014.994633] [PMID: 25471820] 
[6] Dennis MR. Social control of healthy behavior between intimate college students. J Am Coll Health 2011; 59(8): 728-35. [http://dx.doi.org/10.1080/07448481.2010.537419] [PMID: 21950254]

[7] Umberson Debra. 1987.Family Status and Health Behaviors: Social Control as a Dimension of Social Integration

[http://dx.doi.org/10.2307/2136848]

[8] Craddock E, VanDellen MR, Novak SA, Ranby KW. Infl in Relationships: A Meta-Analysis on health-related social control. Basic Appl Soc Psych 2015; 37(2): 118-30. [http://dx.doi.org/10.1080/01973533.2015.1011271]

[9] Krause N, Goldenhar L, Liang J, Jay G, Maeda D. Stress and exercise among the Japanese elderly. Soc Sci Med 1993; 36(11): 1429-41. [http://dx.doi.org/10.1016/0277-9536(93)90385-H] [PMID: 8511631]

[10] Cotter KA, Lancaster NG. A structural equation model examining multiple mediation pathways between social support, exercise selfefficacy, and physical activity. Prevention and health promotion: Research, social action, practice and training 2015; 8(1): 28-42.

[11] Lewis Megan A, Rook Karen S. 1999 Social control in personal relationships: Impact on health behaviors and psychological distress. Health Psychology 18(1): 63-71.

[http://dx.doi.org/10.1037/0278-6133.18.1.63]

[12] Novak Sarah A, Webster Gregory D. Spousal Social Control during a Weight Loss Attempt: A Daily Diary Study. Personal Relationships 18(2): 224-41.2011;

[http://dx.doi.org/10.1111/j.1475-6811.2011.01358.x]

[13] Tucker JS, Orlando M, Elliott MN, Klein DJ. Affective and behavioral responses to health-related social control. Health Psychol 2006; 25(6): 715-22.

[http://dx.doi.org/10.1037/0278-6133.25.6.715] [PMID: 17100500]

[14] Pugliese JA, Okun MA. Social control and strenuous exercise among late adolescent college students: Parents versus peers as influence agents. J Adolesc 2014; 37(5): 543-54.

[http://dx.doi.org/10.1016/j.adolescence.2014.04.008] [PMID: 24931557]

[15] Cotter Kelly A. Health-related social control over physical activity: Interactions with age and sex [special issue]. Journal of Aging Research 2012. article ID 321098.

[http://dx.doi.org/10.1155/2012/321098]

[16] Fekete Erin, Geaghan Thomas R, Druley Jennifer. Affective and behavioral reactions to positive and negative health-related social control in hiv + men. Psychology \& Health 2009; 24(5): 501-15.

[17] Logic Mia, Okun Morris A, Pugliese John A. 2009; Expanding the mediational model of the effects of health-related social control. Journal of Applied Social Psychology 39(6): 1373-96.

[http://dx.doi.org/10.1111/j.1559-1816.2009.00486.x]

[18] Thorpe Carolyn T, Lewis Megan A, Sterba Katherine R. Reactions to Health-Related Social Control in Young Adults with Type 1 Diabetes. Journal of Behavioral Medicine 31(2): 93-103.2008;

[http://dx.doi.org/10.1007/s10865-007-9125-4]

[19] Cohen Sheldon, Lichtenstein Edward. "Partner Behaviors that Support Quitting Smoking J Consul Clin Psychology 58(3): 304-9.1990; [http://dx.doi.org/10.1037/e334492004-009]

[20] Helgeson Vickie S, Novak Sarah A, Lepore Stepehn J, Eton David T. Spouse social control efforts: Relations to health behavior and wellbeing among men with prostate cancer J Social Pers Rel 21(1): 53-68.2004

[http://dx.doi.org/10.1177/0265407504039840]

[21] Lichtenstein Edward, Andrews Judy A, Barckley Maureen, Akers Laure, Severson Herbert H. Women helping chewers: Partner support and smokeless tobacco cessation: Heal Psychol 21(3): 273-8.2002; [http://dx.doi.org/10.1037/0278-6133.21.3.273]

[22] Rice VH, Templin T, Fox DH, et al. Social context variables as predictors of smoking cessation. Tob Control 1996; 5(4): 280-5.https://www.ncbi.nlm.nih.gov/pmc/articles/PMC1759531/pdf/v 005p00280.pdf

[http://dx.doi.org/10.1136/tc.5.4.280] [PMID: 9130361]

[23] Stephens, Mary Ann P., Fekete, Erin M., Franks, Melissa M., Rook, Karen S., Druley, Jennifer A., and Greene, Kenneth. 2009. "Spouses' use of pressure and persuasion to promote osteoarthritis patients' medical adherence after orthopedic surgery. Heal Psychol 28(1): 48-55.

[24] Westmaas J Lee, Wild T Cameron, Ferrence Roberta. "Effects of Gender in Social Control of Smoking Cessation Health Psychology 21(4): 368-76.2002;

[http://dx.doi.org/10.1037/0278-6133.21.4.368]

[25] Khan Cynthia M. Stephens, Mary Ann P., Franks, Melissa M., Rook, Karen S., and Salem, James K. 2013. "Influences of spousal support and control on diabetes management through physical activity Heal Psychol 32(7): 739-47.2013;

[26] Molenaar PC, Campbell CG. The New Person-Specific Paradigm in Psychology. Curr Dir Psychol Sci 2009; 18(2): 112-7. [http://dx.doi.org/10.1111/j.1467-8721.2009.01619.x]

[27] Zawadzki MJ, Mendiola J, Walle EA, Gerin W. Between-person and within-person approaches to the prediction of ambulatory blood pressure: the role of affective valence and intensity. J Behav Med 2016; 39(5): 757-66. epub ahead of print [http://dx.doi.org/10.1007/s10865-016-9746-6] [PMID: 27139080]

[28] Voluntary System of Accountability Program College Portrait. 2012.California State University, Sacramento college portrait Retrieved March 3, 2016 http://www.collegeportraits.org/CA/CSUS/characteristics

[29] Sallis JF, Grossman RM, Pinski RB, Patterson TL, Nader PR. The development of scales to measure social support for diet and exercise behaviors. Prev Med 1987; 16(6): 825-36.

[http://dx.doi.org/10.1016/0091-7435(87)90022-3] [PMID: 3432232]

[30] Maher JP, Doerksen SE, Elavsky S, et al. A daily analysis of physical activity and satisfaction with life in emerging adults. Health Psychol 2013; 32(6): 647-56.

[http://dx.doi.org/10.1037/a0030129] [PMID: 23088171]

[31] Sjöström M, Ainsworth B, Bauman A, Bull F, Craig C, Sallis J. Guidelines for data processing and analysis of the international physical activity questionnaire (ipaq) - short and long forms. Stockholm, Sweden: Karolinska Institute 2005.

[32] Schwartz JE, Stone AA. Strategies for analyzing ecological momentary assessment data. Health Psychol 1998; 17(1): 6-16. [http://dx.doi.org/10.1037/0278-6133.17.1.6] [PMID: 9459065]

[33] Bolger N, Laurenceau J-P. Intensive longitudinal methods an introduction to diary and experience sampling research. New York, NY: Guilford 2013

[34] Singer JD, Willett JB. Applied longitudinal data analysis: Modeling change and event occurrence. New York, NY: Oxford University Press 2003.

[http://dx.doi.org/10.1093/acprof:oso/9780195152968.001.0001]

[35] Cotter KA, Kerschner BJ. Personality and health: Impacts of romantic relationship characteristics. Pers Individ Dif 2018; 120: 40-6. [http://dx.doi.org/10.1016/j.paid.2017.08.023]

[36] Tucker JS. Health-related social control within older adults' relationships. J Gerontol B Psychol Sci Soc Sci 2002; 57(5): 387-95. [http://dx.doi.org/10.1093/geronb/57.5.P387] [PMID: 12198097]

[37] Prochaska JO, DiClemente CC, Norcross JC. In search of how people change. Applications to addictive behaviors. Am Psychol 1992; 47(9): 1102-14.

[http://dx.doi.org/10.1037/0003-066X.47.9.1102] [PMID: 1329589]

\section{C) 2019 Cotter and Mendiola.}

This is an open access article distributed under the terms of the Creative Commons Attribution 4.0 International Public License (CC-BY 4.0), a copy of which is available at: https://creativecommons.org/licenses/by/4.0/legalcode. This license permits unrestricted use, distribution, and reproduction in any medium, provided the original author and source are credited. 